\title{
Overflow probability of the Salt Lake in Hoh Xil Region
}

\author{
YAO Xiaojun ${ }^{1}$, SUN Meiping ${ }^{1,2}$, GONG Peng ${ }^{1}$, LIU Baokang ${ }^{3}$, LI Xiaofeng ${ }^{1}$, \\ AN Lina ${ }^{1}$, YAN Luxia ${ }^{1}$ \\ 1. College of Geography and Environment Sciences, Northwest Normal University, Lanzhou 730070, China; \\ 2. State Key Laboratory of Cryosphere Sciences, Northwest Institute of Eco-Environment and Resources, CAS, \\ Lanzhou 730000, China; \\ 3. Qinghai Institute of Meteorological Sciences, Xining 810001, China
}

\begin{abstract}
After the bursting of Huiten Nor in Hoh Xil Region in September, 2011, the topic on whether the water overflowed from the Salt Lake would enter into the Chumaer River and become the northernmost source of the Yangtze River has aroused wide concern from public and academic field. Based on Landsat TM/ETM+/OLI remote sensing images during 2010-2015, SRTM 1 arc-second data, Google Earth elevation data and the observation data from the Wudaoliang meteorological station, the study initially analyzed the variations of the Salt Lake and its overflowing condition and probability. The results showed that the area of the Salt Lake expanded sharply from October 2011 to April 2013, and then it stepped into a stable expansion period. On October 27, 2015, the area of the Salt Lake had arrived at $151.38 \mathrm{~km}^{2}$, which was about 3.35 times the area of the lake on March 3, 2010. The Salt Lake will overflow when its area reaches the range from $218.90 \mathrm{~km}^{2}$ to $220.63 \mathrm{~km}^{2}$. Due to the differences between SRTM DEM and Google Earth elevation data, the water level of the Salt Lake simulated would be $12 \mathrm{~m}$ or $9.6 \mathrm{~m}$ higher than the current level when the lake overflowed, and its reservoir capacity would increase by $23.71 \mathrm{~km}^{3}$ or $17.27 \mathrm{~km}^{3}$, respectively. Meanwhile, the overflowed water of the Salt Lake would run into the Qingshui River basin from its eastern part. Although the Salt Lake does not overflow in the coming decade, with watershed expansion of the Salt Lake and the projected precipitation increase in Hoh Xil region, the probability of water overflow from the Salt Lake and becoming a tributary of the Yangtze River will exist in the long term.
\end{abstract}

Keywords: water overflow; reservoir capacity; Salt Lake; Hoh Xil; Tibetan Plateau

\section{Introduction}

The Huiten Nor located in Hoh Xil Region broke on September 14, 2011, then the flood flowed into the Kusai Lake along the gully and Kusai River (Yang, 2015). Due to the quick

Received: 2017-05-17 Accepted: 2017-07-20

Foundation: National Natural Science Foundation of China, No.41261016, No.41561016; Opening Foundation Projection of State Key Laboratory of Cryosphere Sciences, CAS, No.SKLCS-OP-2016-10; Youth Scholar Scientific Capability Promoting Project of Northwest Normal University, No.NWNU-LKQN-14-4

Author: Yao Xiaojun (1980-), PhD and Associate Professor, specialized in GIS and cryospheric change. E-mail: xj_yao@nwnu.edu.cn 
rise of water level, the Kusai Lake started to overflow from September 20 to 30, 2011, and made a chain process of lake water spillover in its downstream (Yao et al., 2012). Finally, the Salt Lake on the east of the Haiding Nor received the spillover water. Up to now, the reasons of the Huiten Nor outburst are still controversial. Yao et al. $(2012,2013)$ thought that the main reasons were the increase of precipitation and the decrease of evaporation in Hoh Xil Region. Yang (2015) believed that this event was caused by the headward erosion of seasonal river in the palaeochannel. However, there is no doubt that the hydraulic connection was built among the four lakes including the Huiten Nor, Kusai Lake, Haiding Nor and Salt Lake because the Huiten Nor broke. If the area of the Salt Lake which is the last "recipient" of surface runoff in the basin continues to increase, will the situation like the Kusai Lake and Haiding Nor overflow occur? Once the overflowing water of the Salt Lake enters into the Qumar River along the Qingshui River, the Zhuonai River will be the most northern origin of the Yangtze River. Additionally, because the four lakes mentioned above belong to brackish lake or salt lake with higher mineralization (Hu, 1992; Wang and Dou, 1998), lake water overflowed can not only affect the water quality and ecological environment of the Yangtze River, but also increase the thickness of permafrost active layer in the area drained by lake water (Wu and Niu, 2013), which will eventually endanger some projects including the Qinghai-Tibet railway and highway in this region (Cheng, 2003). To answer these questions, it is the key to recognize the change of the Salt Lake and judge the possibility of lake water overflow.

\section{Study area}

The Salt Lake $\left(35^{\circ} 32^{\prime} \mathrm{N}, 93^{\circ} 25^{\prime} \mathrm{E}\right)$ was named for its salt production, and was also named as 68 Dao Ban Salt Lake. It lies in the northeast part of the Hoh Xil National Nature Reserve and is about $12 \mathrm{~km}$ away from the Sonam Dhargey protection station in Zhidoi County of Qinghai Province (Figure 1). The Salt Lake is formed in the Tertiary continental downfaulted basin in the middle of the Kunlun Mountains and is surrounded by monadnocks composed of Tertiary-Pliocene continental stratas. The lakefront is Quaternary-Holocene lacustrine and paludal sediments and the lake water is mainly supplied by seasonal rivers. There were two rock islands in the middle of the lake, which were inundated in 2012 due to the rise of lake water level. The lake region belongs to Alpine Steppe semi-arid climate with the average annual temperature ranging from -4.0 to $-1.0^{\circ} \mathrm{C}$ and the annual precipitation of 150-200 mm. According to Records of Chinese Lakes (Wang and Dou, 1998), the mineralization degree of the Salt Lake is up to $221.35 \mathrm{~g} / \mathrm{L}$ and belongs to magnesium sulphate $\left(\mathrm{MgSO}_{4}\right)$ subtype salt lake. The brine made up of sodium sulphate $\left(\mathrm{NaSO}_{4}\right)$ and carbonate is developed locally, and the salt minerals are halite, mirabilite and gypsum. The Salt Lake was exploited in the 1980s and the salt was transported to the Shigatse Prefecture in Tibet Autonomous Region ( $\mathrm{Hu}, 1992)$. With the establishment of the Hoh Xil National Nature Reserve, salt mining activities had stopped.

In the northwest of the Salt Lake, there are Haiding Nor, Kusai Lake and Huiten Nor from east to west (Figure 2), which belonged to closed-basin lakes before the outburst of Huiten Nor in Spetember 2011. The Huiten Nor is mainly supplied by the Huiten River originated from glacial melt water in Wuxuefeng region. The Kusai Lake relies on the Kusai River in the southern part of Kunlun Mountains. The intermittent stream and surface runoff constitute 


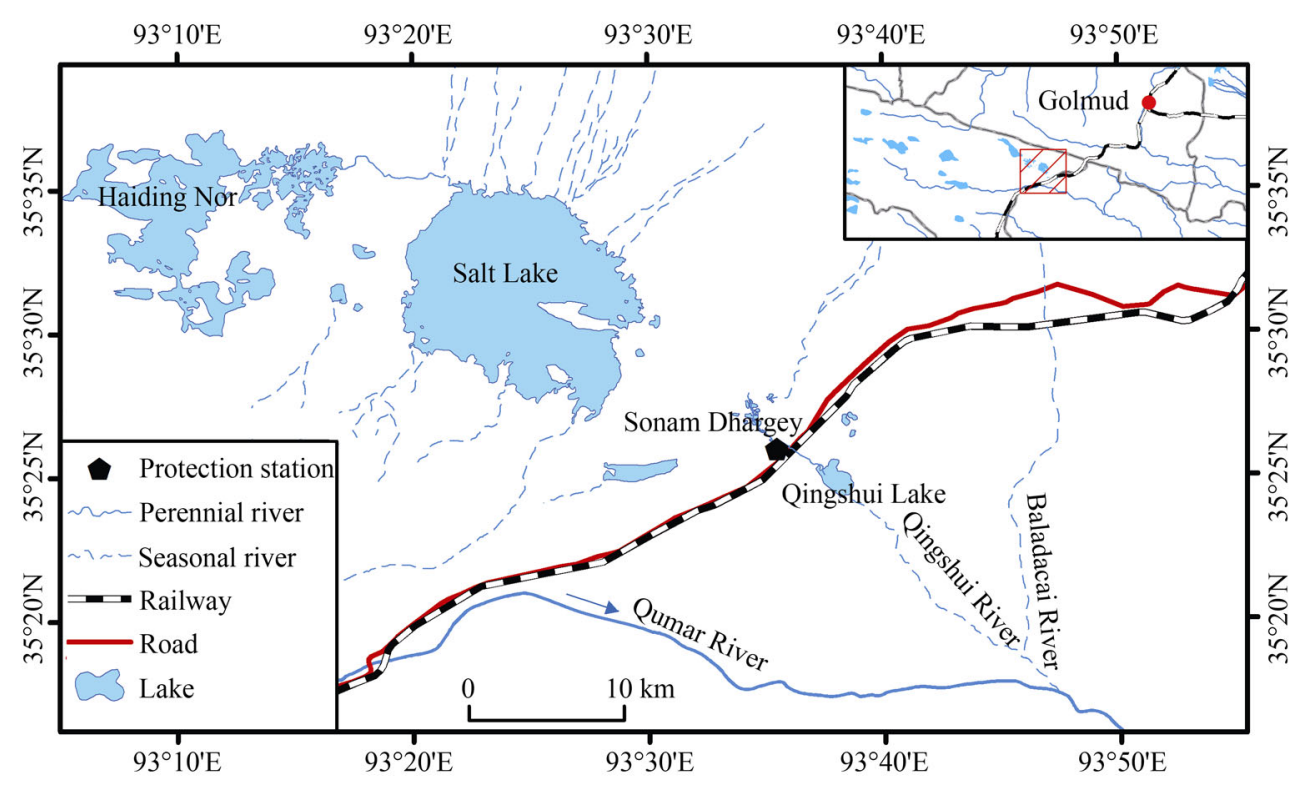

Figure 1 The map of Salt Lake

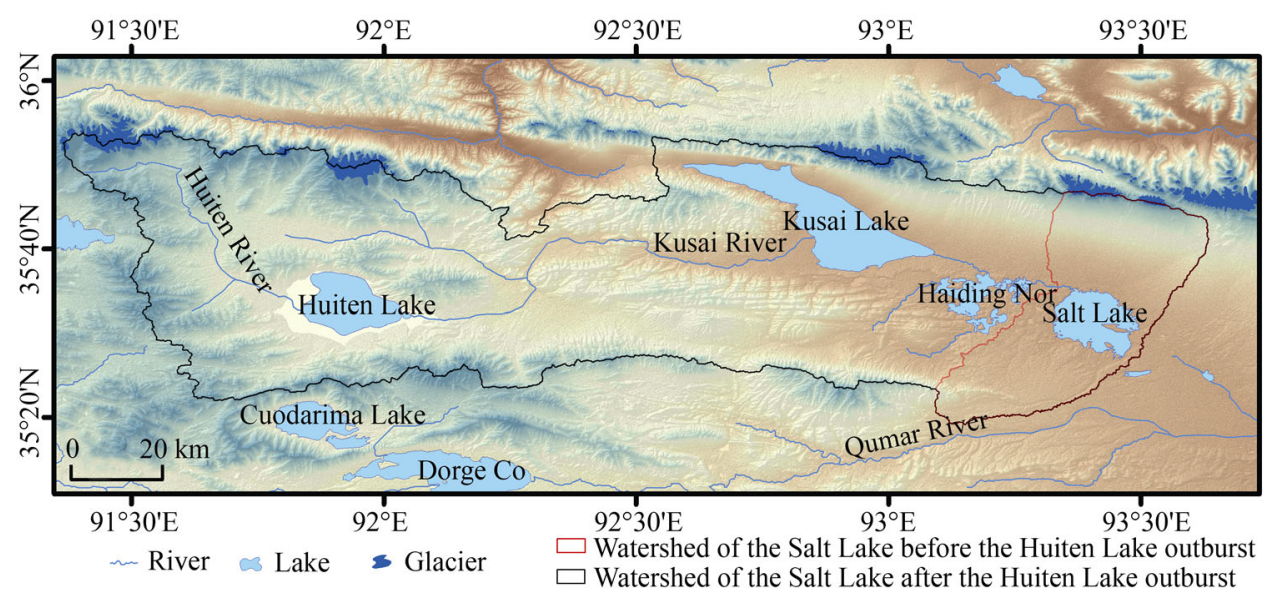

Figure 2 Lakes in the neighborhood of the Salt Lake

the main water source of the Haiding Nor. After the outburst of the Huiten Nor, the chain reaction of water spillover from the Kusai Lake and Haiding Nor made the Salt Lake expand rapidly and formed some river channels between each other (Yao et al., 2012).

\section{Data and methods}

\subsection{Data sources}

In order to obtain the change of the Salt Lake, 81 Landsat TM/ETM+/OLI remote sensing images from 2010 to 2015 were collected and processed. These remote sensing images with the path/row of 137035 and 138035 were downloaded from the USGS website (http://glovis.usgs.gov). There are many advantages to selecting the Landsat TM/ETM+/OLI images as the basic data sources. For example, these images were preprocessed by geometric 
correction which helped to reduce the workload; the error caused by the scan line corrector off in Landsat ETM+ after 2003 could be diminished by the combination of Landsat TM and OLI images; the accuracy of lake interpretation could be improved by cross validation of multi-source remote sensing images. Due to the cover of cloud and snow on the Salt Lake, there were fewer remote sensing images with high quality in four months including June, July, September and December, having amount were 4, 5, 3 and 3 scenes, respectively.

The digital elevation model (DEM) data used in this study included the Shuttle Radar Topography Mission (SRTM) 1 arc-second DEM and Google Earth elevation data. The spatial resolution of the former was about $30 \mathrm{~m}$, which were collected through the SRTM system carried by the space shuttle Endeavour in February 2000 and were published by NASA in the late 2014 (http://www2.jpl.nasa.gov). The aerial photographs, satellite remote sensing images and geographical information system (GIS) data were integrated in the Google Earth software, which had been widely used in some fields, such as the arrangement of GPS control network, the production of thematic maps and the survey of large scale terrain, etc (Huang and Zhang, 2015). Meanwhile, the Google Earth API was freely provided to help developers carry out the secondary development to extract relevant information (Mo et al., 2012). Some studies demonstrated that the topographic feature lines derived from Google Earth elevation data were consistent with its images, and the accuracy of elevation was better than topographic maps with the scale of 1:50 000 (Guan and Fang, 2011; Huang and Zhang, 2015). The spatial resolution of Google Earth elevation data available in this study area was about $15 \mathrm{~m}$. In addition, the observation data from Wudaoliang meteorological station near the Salt Lake was selected as the reference of climate change, and this dataset was provided by China Meteorological Data Service Center (http://data.cma.cn).

\subsection{Methods}

Water body has strong absorption at the near infrared band and strong reflectivity at the blue band, so it is easier to be identified or extracted by means of band combinations or band operations. Currently, the commonly used methods for identifying the lake water include artificial visual interpretation, Normalized Difference Water Index (NDWI) and Modified Normalized Difference Water Index (MNDWI). The main difference between NDWI and MNDWI is the choice of near infrared band and mid-infrared band (Mcfeeters, 1996; Xu, 2005). In this study, the boundary of Salt Lake only needed be extracted to obtain its areas in different periods. Experiments showed that the workload of remote sensing image preprocessing and post-processing using NDWI and MNDWI methods was more than the digitalization by artificial visual interpretation. So the method of artificial visual interpretation was adopted and the extraction accuracy was limited to one pixel.

Based on the acquisition of the Salt Lake's boundaries and the assumption of water level being stable in the moment of acquisition date of remote sensing image, the change of water level in different periods could be obtained by iteratively increasing the elevation value (e.g. $0.1 \mathrm{~m}$ for Google Earth elevation data and $1 \mathrm{~m}$ for SRTM DEM, respectively) which extent was same as the interpretation result of the Salt Lake from the remote sensing images, and then the change of lake reservoir capacity could been calculated by raster algebra function in the ArcGIS software. The formula is as follows:

$$
\Delta V=\left(S_{i} \times\left(h_{j}-h_{i}\right)+\left(S_{j}-S_{i}\right) \times\left(h_{j}-h_{D E M}\right)\right) / 1000
$$


where $\Delta V$ is the change of lake reservoir capacity $\left(\mathrm{km}^{3}\right) ; S_{i}$ and $S_{j}$ are areas of the lake $\left(\mathrm{km}^{2}\right)$ for date $i$ and $j$, respectively; $h_{i}$ and $h_{j}$ are lake water levels (m) for date $i$ and $j$, respectively; $h_{D E M}$ is the elevation (m) which is not overwhelmed at the $i$ moment.

Finally, the ridge between the Salt Lake and the Qingshui River watershed was derived by using the hydrology model in the ArcGIS software. Then the maximum extent of the Salt Lake was simulated by looping the elevation until the lake water overflowing into the Qingshui River watershed. The volume increment of lake water meeting this condition could be calculated by formula (1).

\section{Results and discussion}

\subsection{Spatiotemporal variations of the Salt Lake from 2010 to 2015}

The Salt Lake experienced a dramatic variation from 2010 to 2015 (Figure 3). Before the water from the Haiding Nor flowed into the Salt Lake in October 2011, the Salt Lake expanded slowly. Its area was $45.18 \mathrm{~km}^{2}$ on March 3, 2010 and $47.61 \mathrm{~km}^{2}$ on October 29, 2010, respectively. The percentage of area variation of the Salt Lake was only $5.37 \%$ and it enlarged toward the northeast during this period. On November 9, 2011, the area of Salt Lake increased to $73.18 \mathrm{~km}^{2}$. Then the Salt Lake entered into a period of rapid expansion. Its area was $84.29 \mathrm{~km}^{2}$ on December 11, 2011 and $99.33 \mathrm{~km}^{2}$ on May 19, 2012, respectively. Until October 26, 2012, the area of Salt Lake increased to $134.19 \mathrm{~km}^{2}$ which was nearly 3 times that on October 29, 2010. After April 12, 2013, the Salt Lake switched to a relatively slow expansion which growth speed $\left(3.43 \mathrm{~km}^{2} / \mathrm{a}\right)$ was yet greater than that before $2011(2.43$ $\mathrm{km}^{2} / \mathrm{a}$ ). Meanwhile, 9 islands were formed in the eastern, western and southern parts of the lake and the largest one had an area of $0.53 \mathrm{~km}^{2}$. The area of Salt Lake increased to 151.38 $\mathrm{km}^{2}$ on October 27, 2015, which was consistent with the interpretation result based on HJ1A/B remote sensing images (Liu et al., 2016).
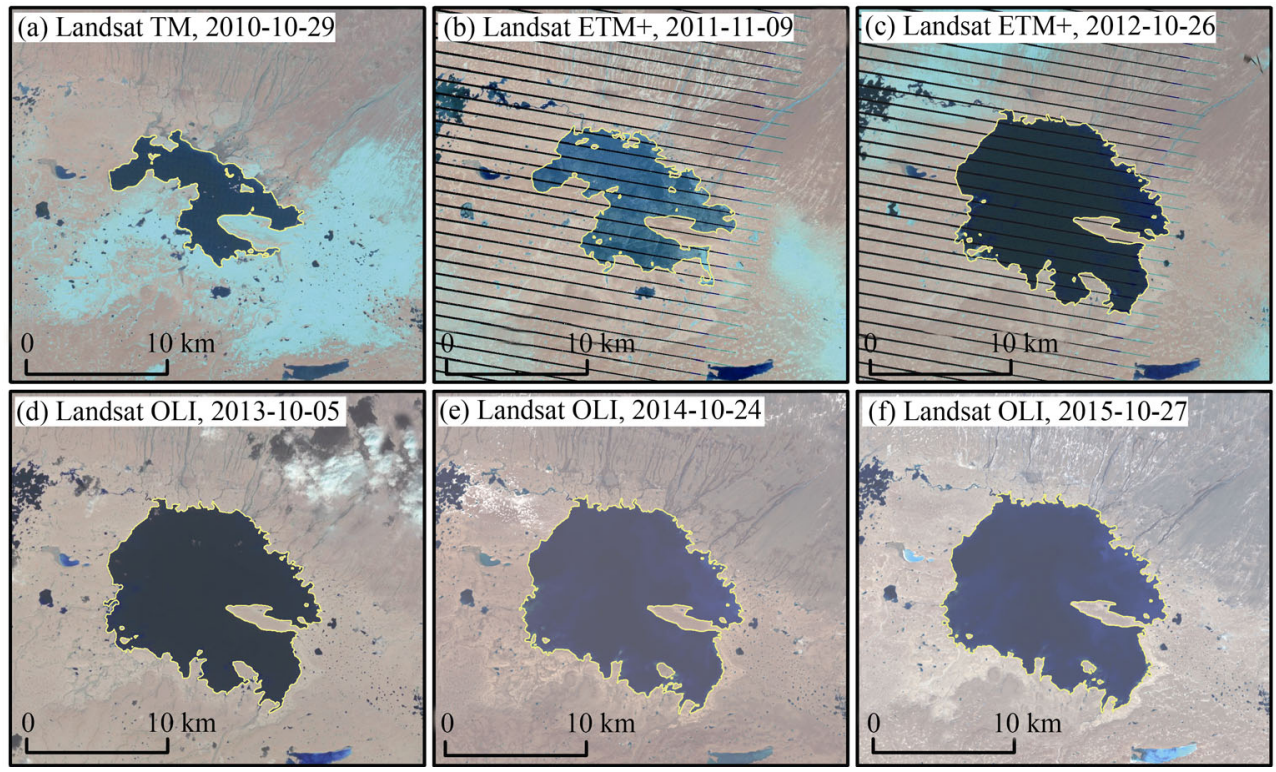

Figure 3 Variations of the Salt Lake from 2010 to 2015 
The variation trend of reservoir capacity of the Salt Lake was same as that of its area during the period of 2010-2015 (Table 1). Due to the difference of data type (e.g. the values of SRTM DEM and Google Earth elevation data were integer and float, respectively), the reservoir capacity calculations of the Salt Lake based on SRTM DEM were generally greater than that based on Google Earth elevation data, but their trends were consistent. It was noted that the changes of reservoir capacity based on Google Earth elevation data in 2010 and from 2014 to 2015 could not been obtained because of its limitation of data precision. Specifically, the variations of reservoir capacity were $23.84 \times 10^{8} \mathrm{~m}^{3}$ and $18.88 \times 10^{8} \mathrm{~m}^{3}$ from October 29, 2010 to October 24, 2014 based on SRTM DEM and Google Earth elevation data, respectively. On the consideration of interception of the Kusai Lake and the Haiding Nor on the overflowing water from the Huiten Nor (the areas of the Kusai Lake and the Haiding Nor actually increased after the outburst of the Huiten Nor) (Yao et al., 2012), the outburst flood amount of the Huiten Nor would exceed the value estimated by Yang (2015). As mentioned above, the Salt Lake turned to a situation of relatively slow expansion after April 12, 2013, for example, the lake undergone small variations from September 5, 2013 to September 30, 2015 and had a steady area of about $161 \mathrm{~km}^{2}$ (Liu et al., 2016). It implied the rapid area increase of the Salt Lake caused by the Huiten Nor outburst flood terminated and the Salt Lake would be supplied by the surface runoff in the basin. The area and reservoir capacity variations of the Salt Lake after 2013 were much more than that before the Huiten Nor outburst which made the watersheds of the Huiten Nor, Kusai Lake, Haiding Nor and Salt Lake merge into one (Figure 2). The fact was that the area of the Salt Lake watershed rapidly increased from $1261.64 \mathrm{~km}^{2}$ to $8563.54 \mathrm{~km}^{2}$. Except for the surface runoff in its own watershed, the Salt Lake received the upstream water from the Haiding Nor through the newly formed river channel. Compared with the reservoir capacity variation of the Salt Lake before 2010, its water amount from the Haiding Nor and its upstream basin was between $1.20 \times 10^{8}$ and $1.78 \times 10^{8} \mathrm{~m}^{3}$ and became an important water source of the Salt Lake.

Table 1 Reservoir capacity variations of the Salt Lake from 2010 to 2015

\begin{tabular}{lcc}
\hline \multicolumn{1}{c}{ Period } & $\begin{array}{c}\text { Variations based on } \\
\text { SRTM DEM }\left(10^{8} \mathrm{~m}^{3}\right)\end{array}$ & $\begin{array}{c}\text { Variations based on } \\
\text { Google Earth DEM }\left(10^{8} \mathrm{~m}^{3}\right)\end{array}$ \\
\hline March 3, 2010-October 29, 2010 & 0.80 & - \\
October 29, 2010-November 9, 2011 & 4.46 & 5.64 \\
November 9, 2011-May 19, 2012 & 6.08 & 10.66 \\
May 19, 2012-October 26, 2012 & 10.72 & 0.56 \\
April 12, 2013-October 24, 2014 & 2.58 & - \\
October 24, 2014-October 27, 2015 & 2.00 & - \\
\hline
\end{tabular}

Note: "-" denotes that the variation of reservoir capacity cannot be calculated due to the sameness of DEM maximum value in different periods.

\subsection{Condition of water overflow from the Salt Lake}

The condition of water overflow from the Salt Lake is that its boundary leaps over the ridge between the Salt Lake and Qingshui River basin, which can be simulated by iteratively setting increase of lake water level. Figure 4 showed that the expansion range of the Salt Lake meeting this condition based on SRTM DEM and Google Earth elevation data. It was obvious that the Salt Lake would expand around and the narrow southeastern part would evolve 
into an island. The area of the overflowed Salt Lake simulated was $220.63 \mathrm{~km}^{2}$ based on SRTM DEM and $218.90 \mathrm{~km}^{2}$ based on Google Earth elevation data, respectively. And the water level of the Salt Lake would expect to be $4473 \mathrm{~m}$ (SRTM DEM) and $4476.3 \mathrm{~m}$ (Google Earth elevation data) which was $12 \mathrm{~m}$ and $9.6 \mathrm{~m}$ higher than now. It was consistent with the fact that there were many lower ridges between lakes in northern Tibet (Yang, 2015). Similar to the results in Table 1, the increment of reservoir capacity calculated by SRTM DEM was greater than that by Google Earth elevation data. The former was 23.71 $\mathrm{km}^{3}$ and the latter was $17.27 \mathrm{~km}^{3}$. It should be pointed out that the water from the Salt Lake would flow into the Qingshui River basin in the vicinity of location $\left(35^{\circ} 28^{\prime} 47^{\prime \prime} \mathrm{N}\right.$, $\left.93^{\circ} 30^{\prime} 10^{\prime \prime} \mathrm{E}\right)$ if it came true.

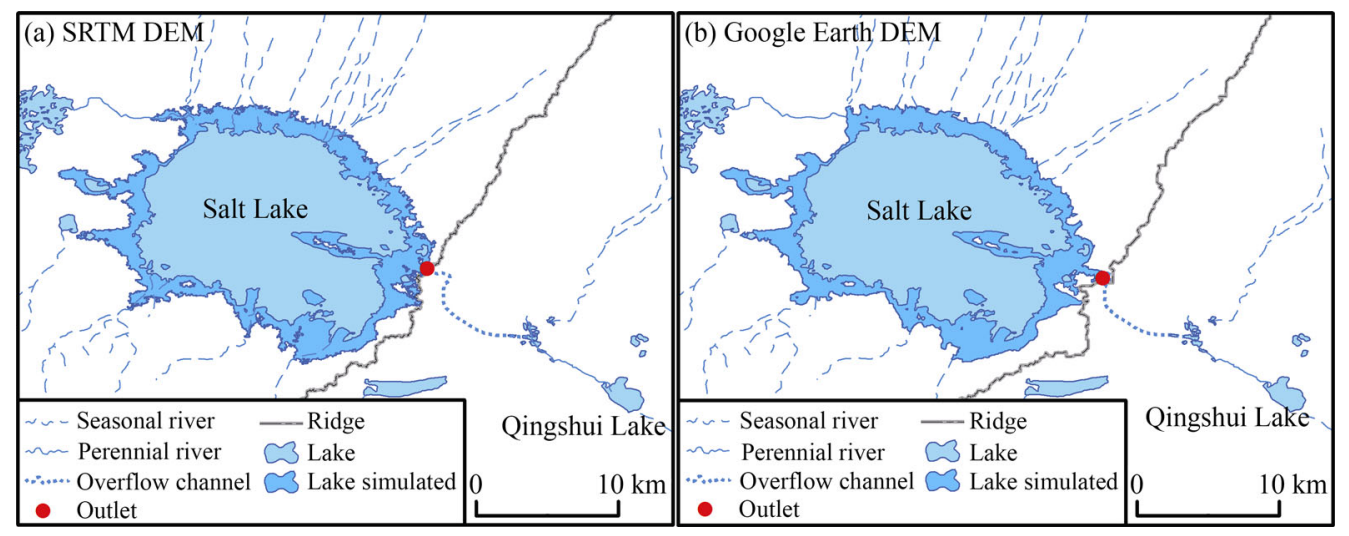

Figure 4 The expansion range of the overflowed Salt Lake

\subsection{Overflow probability of the Salt Lake}

The observation data of Wudaoliang meteorological station showed that the precipitation fluctuated from 1970 to 1995 and the average annual precipitation was $264.8 \mathrm{~mm}$ (Figure 5). There was an obvious upward trend of precipitation after 1996; especially the average annual precipitation was as high as $383.2 \mathrm{~mm}$ during the period 2008-2014, with an increase of $44.71 \%$ than that before 1995 . Numerous studies showed that the precipitation over the Tibetan Plateau would increase in the first half of the 21 st century, and the northern and western parts of the Tibetan Plateau belonged to the precipitation amplification regions (Chen et al., 2011; Su et al., 2013; Zhang et al., 2015). In RCP 2.6 and RCP 8.5 scenarios, the average annual precipitation of Tibetan Plateau during the period 2006-2035 was expected to increase by $3.2 \%$ relative to the base period 1961-2005 ( $\mathrm{Su}$ et al., 2013). In RCP 4.5 scenario, the average annual precipitation of Tibetan Plateau during the period 2016-2035 would also increase by $4.4 \%$ relative to the reference period of 1986-2005 (Hu et al., 2015). If the precipitation in Hoh Xil Region increases in the next few decades as expected, the Salt Lake will continue to expand and its water will finally enter into the Qingshui River basin.

Assuming that there are no more lake outburst floods in the upstream of Salt Lake and the increment of reservoir capacity remains constant being $2.00 \mathrm{~km}^{3}$ during the period 2014-2015, the water of the Salt Lake will flow into the Qingshui River basin in September 2026 based on SRTM DEM, which means the time needed is 11.86 years. The result simulated by Google Earth elevation data showed that the period was 30.83 years, e.g. the late 


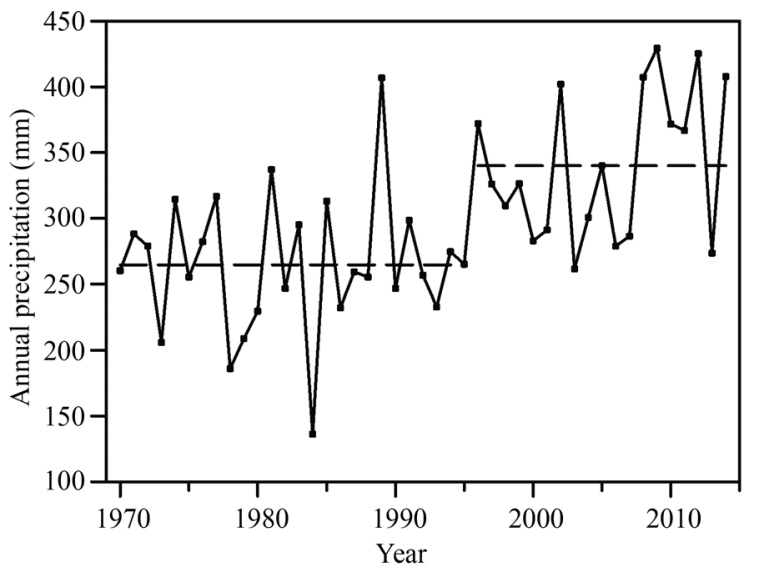

Figure 5 Precipitation variation observed at Wudaoliang meteorological station from 1970 to 2014

September 2045. Not considering evaporation, surface seepage and interception, that is to say, all precipitation in the basin flows into the Salt Lake and there is no water loss, the runoff depth needed will reach $2.77 \times 10^{3} \mathrm{~mm}$ (SRTM DEM) or $2.02 \times 10^{3} \mathrm{~mm}$ (Google Earth elevation data). Based on the average annual precipitation of Wudaoliang meteorological station with a value of $296.6 \mathrm{~mm}$ from 1970 to 2014 and $383.2 \mathrm{~mm}$ from 2008 to 2014, respectively, the time needed will be 5.26 years at the least and 9.33 years at the most. The average annual potential evapotranspiration of Wudaoliang meteorological station calculated by Penman-Monteith formula was much larger than the annual precipitation, although it had a downward trend (Yao et al., 2013). It meant the latter case would not happen in reality. Therefore, it is believed that the Salt Lake will not overflow in the next decade, but this possibility still remains over a longer period.

\section{Conclusions}

In this paper, the variation characteristics of the Salt Lake during the period 2010-2015 and its overflow probability was systematically analyzed based on multi-source remote sensing images and two DEM datasets. Conclusions were drawn as follows:

(1) The Salt Lake in Hoh Xil Region had undergone dramatic changes from 2010 to 2015. According to the speed of lake area increase, its evolution could be divided into three processes: a slow expansion caused by precipitation increase before October 2011; a sharp area increase of lake resulted by the Huiten Nor outburst flood and consecutively water overflow of the Kusai Lake and Haiding Nor; a higher stable expansion caused by the enlargement of watershed after April 2013. Until October 27, 2015, the area of the Salt Lake reached 151.38 $\mathrm{km}^{2}$ which was about 3.35 times the area on March 3, 2010. The increment of reservoir capacity was $18.88 \times 10^{8}-23.84 \times 10^{8} \mathrm{~m}^{3}$ during the period from October 29,2010 to October 24, 2014, based on SRTM DEM and Google Earth elevation data, respectively.

(2) When the area of the Salt Lake increased to $218.90-220.63 \mathrm{~km}^{2}$, its water would enter into the Qingshui River basin. Due to the differences between SRTM DEM and Google Earth elevation data, the water level of the Salt Lake simulated would be $12 \mathrm{~m}$ (SRTM DEM) or $9.6 \mathrm{~m}$ (Google Earth elevation data) higher than the current level when the lake overflowed, and its reservoir capacity would increase by $23.71 \mathrm{~km}^{3}$ or $17.27 \mathrm{~km}^{3}$, respectively. 
(3) The results simulated under different assumptions showed that the Salt Lake would not overflow in the next decade. However, all projected precipitation in different RCP scenarios was expected to increase in the northern part of the Tibetan Plateau where the Salt Lake located in the early 21 st century, as a result, the possibility of lake overflowing and becoming a tributary of the Yangtze River would exist in the longer period.

(4) Due to some limitations such as expensive DEM data, confidential large scale topographic maps and unavailable field measurements data in sparsely-populated region, there maybe a difference between the simulation result of the Salt Lake and its coming evolution. In order to acquire the variation of the Salt Lake and avoid the potential threat to the Qinghai-Tibet railway and highway in this region, the remote sensing monitoring and field investigation of the Salt Lake should been carried out in the future. Meanwhile, the change of permafrost active layer caused by climate warming should be paid more attention in this region.

\section{References}

Chen W, Jiang Z, Li L, 2011. Probabilistic projections of climate change over China under the SRES A1B scenario using 28 AOGCMs. Journal of Climate, 24(17): 4741-4756.

Cheng G D, 2003. Effect of partial factors on permafrost distribution and its suggestion on the Qinghai-Xizang Railway design. Science in China (Series D), 33(6): 602-607. (in Chinese)

Guan J C, Fang C M, 2011. A Google Earth based new approach to pre-treatment of terrain for river simulation. Water Resources and Hydropower Engineering, 42(12): 21-24. (in Chinese)

Hu D S, 1992. Investigation and study on lake resources in Kekexili region. Arid Land Geography, 15(3): 50-58. (in Chinese)

Hu Q, Jiang D B, Fan G Z, 2015. Climate change projection on the Tibetan Plateau: Results of CMIP5 models. Chinese Journal of Atmospheric Sciences, 39(2): 260-270. (in Chinese)

Huang Q, Zhang Z Y, 2015. A method for earth surface elevation obtained based on Google Earth and its accuracy assessment. Bulletin of Surveying and Mapping, (2): 51-54. (in Chinese)

Liu B, Du Y, Li L et al., 2016. Outburst flooding of the moraine-dammed Zhuonai Lake on Tibetan Plateau: Causes and impacts. IEEE Geoscience and Remote Sensing Letters, 13(4): 570-575.

Mcfeeters S K, 1996. The use of the Normalized Difference Water Index (NDWI) in the delineation of open water features. International Journal of Remote Sensing, 17(7): 1425-1432.

Mo S J, Li Z L, Chen C J et al., 2012. 3D terrain modeling based on Google Earth: Method and realization. Bulletin of Surveying and Mapping, (2): 39-42. (in Chinese)

Su F, Duan X, Chen D et al., 2013. Evaluation of the global climate models in the CMIP5 over the Tibetan Plateau. Journal of Climate, 26(10): 3187-3208.

Wang S M, Dou H S, 1998. Records of Chinese Lakes. Beijing: Science Press, 481-493. (in Chinese)

Wu Q B, Niu F J, 2013. Permafrost changes and engineering stability in Qinghai-Xizang Plateau. Chinese Science Bulletin, 58(2): 115-130. (in Chinese)

Xu H Q, 2005. A study on information extraction of water body with the Modified Normalized Difference Water Index (MNDWI). Journal of Remote Sensing, 9(5): 589-595. (in Chinese)

Yang Y, 2015. No trifle on the Qinghai-Tibet Plateau: The Zhuonai Lake is flooding. Chinese National Geography, 661: 78-93. (in Chinese)

Yao X J, Liu S Y, Sun M P et al., 2012. Changes of Kusai Lake in Hoh Xil Region and causes of its water overflowing. Acta Geographica Sinica, 67(5): 689-698. (in Chinese)

Yao X J, Liu S Y, Sun M P et al., 2013. Spatial-temporal variations of lake area in Hoh Xil Region in the past 40 years. Acta Geographica Sinica, 68(7): 886-896. (in Chinese)

Zhang R H, Su F G, Jiang Z H et al., 2015. An overview of projected climate and environmental changes across the Tibetan Plateau in the 21st century. Chinese Science Bulletin, 60(32): 3036-3047. (in Chinese) 